\title{
A evolução dos conceitos de product placement nas produções audiovisuais
}

THE EVOLUTION OF PRODUCT PLACEMENT CONCEPTS IN AUDIOVISUAL PRODUCTIONS

\section{Marcelo Eduardo Ribaric}

Publicitário, produtor audiovisual, Graduado em Comunicação Social/Publicidade e Propaganda, especialista em Comunicação e Marketing e em Comunicação em Mídias Interativas, Mestre em Comunicação e Práticas de Consumo, Doutor em Comunicação e Linguagens (Estudos em Cinema), professor pesquisador do Centro Universitário Autônomo do Brasil (UNIBRASIL). Posdoutorando em Comunicação, Cultura e Artes na Universidade do Algarve.

E-mail: mribaric@gmail.com

Recebido em 03/06/2018. Aprovado em 11/09/2018.

\section{Resumo}

Nas últimas décadas, mudanças no panorama da mídia provocaram revisões de como os consumidores usam a mídia e interagem com as marcas. Consequentemente, os objetivos de comunicação da publicidade e do marketing evoluíram e surgiram novas estratégias para se adaptar a ambientes alterados. Acredita-se que novos tipos de mídia, como mundos virtuais online, blogs, sites de redes sociais e Youtube, ainda precisam ser encapsulados dentro do domínio de definição de Product Placement existente. Este artigo revisa e critica as definições postuladas de Product Placement com o objetivo de dar clareza a este domínio.

Palavras-chave: Publicidade. Consumo. Product placement. Cinema. Posicionamento de marca.

\begin{abstract}
In recent decades, changes in the media landscape have led to revisions of how consumers use the media and interact with brands. As a result, advertising and marketing communication goals have evolved and new strategies have emerged to adapt to changing environments. It is believed that new media types, such as online virtual worlds, blogs, social networking sites and Youtube, still need to be encapsulated within the existing Product Placement definition domain. This article reviews and criticizes the postulated definitions of Product Placement in order to give clarity to this domain.
\end{abstract}

Keywords: Advertising. Consumption. Product placement, cinema, brand positioning. 


\section{Introdução}

Como o próprio nome diz Product ou Brand Placement, é a colocação de produtos ou marcas dentro de uma ação de algum produto midiático, sejam estes peças de teatro, obras de literatura ou artes plásticas, músicas, notícias ou audiovisuais. Seu uso é uma prática muito antiga, tanto no ocidente como no oriente. Também chamado de embedded marketing, o product ou brand placement ele se caracteriza por ser uma ação híbrida entre a publicidade e as relações públicas, o que assegura uma combinação dos pontos fortes da publicidade, como o controle sobre a mensagem, e das relações públicas, a credibilidade da informação, ao mesmo tempo em que evita as principais desvantagens destas duas áreas da comunicação - a falta de credibilidade da fonte de informação, no caso da publicidade, e a quase ausência de capacidade de influência sobre o conteúdo, forma e calendarização da mensagem, no caso das relações públicas.

Balasubramanian (1994, p. 29) usou o termo "benefício-mix" para descrever os esforços organizacionais que combinam os aspectos da publicidade e da publicity ${ }^{l}$ para utilizar as vantagens de cada um, evitando suas respectivas deficiências. Embora a publicidade permita que as organizações tenham controle sobre sua mensagem e sua disseminação, ela é frequentemente vista como menos credível junto ao público. Com publicity, as organizações trabalham através da mídia para transmitir mensagens (ou esforços de branding). Embora as organizações renunciem a algum grau de controle sobre a mensagem (ou representação da marca), acredita-se que a mensagem é vista como sendo mais confiável, pois é disseminada pela mídia e não por uma organização (Guth \& Marsh, 2003). As mensagens que atingem esse mix de benefícios são conhecidas como "mensagens híbridas", uma colocação de produto, ou uma mensagem de produto paga destinada a influenciar o público de cinema ou televisão através da entrada planejada e discreta de um produto ou marca em um filme ou programa de televisão (BALASUBRAMANIAN, 1994).

Embora o termo product placement só comece a ser utilizado anos 1980 (NEWELL; SALMON; CHANG, 2006), o seu uso realmente remonta a antes do nascimento do cinema. Existem exemplos claros de product placement em performances de palco e arte que antecedem os filmes (LEHU, 2007). Na pintura Un bar aux Folies-Bergère (1882), de Edouard Manet, por exemplo, aparece na pintura a imagem da cerveja Bass.

1. Publicity é um termo em inglês que não possui uma palavra semelhante em português. Segundo o dicionário de termos da AMA (American Marketing Association), significa - A comunicação de informações não paga sobre uma empresa ou produto, geralmente em alguma forma de mídia. 
Conforme mostram os estudos de Adam Lewis Kern (1997), no Japão do século XVIII, Santo Kyoden, um popular escritor de ficção gesaku e kibyōshi (livros de imagens satíricas), sharebon (livros espirituosos sobre moda), kokkeibon (ficção cômica), hanashibon (livros humorísticos) e yomihon (livros de leitura), também conhecido por ilustrar suas obras, inseria informações sobre sua própria loja de tabaco nas histórias que escrevia. E no século início do século XIX (CARLYON, 2001), um famoso palhaço dos Estados Unidos, conhecido pelos seus espetáculos equestres, chamado Dan Rice, era contratado para andar pelas ruas das cidades cantando músicas, em cujas letras, ele inseria os nomes de hotéis e restaurantes locais.

Ainda no século início do século XIX, Charles Dickens, na Inglaterra, lança seu romance The Pickwick Papers. Escrito em 1836, o livro narra as aventuras do grupo de estudo Clube Pickwick, composto pelo líder, Sr. Pickwick, e seus três pupilos, que viajavam pela Inglaterra em busca de descobertas científicas e analisando o comportamento das populações. Esta obra foi financiada por uma empresa de carruagens da época a Pickwick Company, que deu nome ao romance.

No cinema a prática do product placement, teve início já no chamado "primeiro cinema" (1895-1910) com os irmãos Lumiérè (Imagem 1). Em 1927, o filme Wings, dirigido por William Wellman e Harry d'Arrasto, além de ser o primeiro filme a ganhar o Oscar, apresentou uma cena na qual o personagem principal comia uma barra de chocolate da Hershey's e com direito a um plano detalhe da embalagem. No entanto, apenas na década de 1980 que o product placement realmente se destacou enquanto prática mercadológica a partir do filme "E.T.: The Extra-Terrestrial" (E.T.: O Extraterrestre), do cineasta Steven Speilberg, novamente com a marca Hershey's, desta vez introduzindo o doce Reese's Pieces. E conforme Reed, (1989), duas semanas após o lançamento do filme, a Hershey apresentou um aumento de $65 \%$ nas vendas do doce.

O product placement em programas de televisão é tão popular quanto no cinema. Um dos mais notáveis acordos de patrocínio ou product placement de televisão atual é o do reality show de culinária, MasterChef Austrália. Marcas notáveis como Sunbeam, Coles, MasterFoods e Qantas constantemente aparecem durante as competições (MASTERCHEF AUSTRALIA, 2012). 
Figura 1 - Fotograma do filme dos irmão Lumiérè de 1896

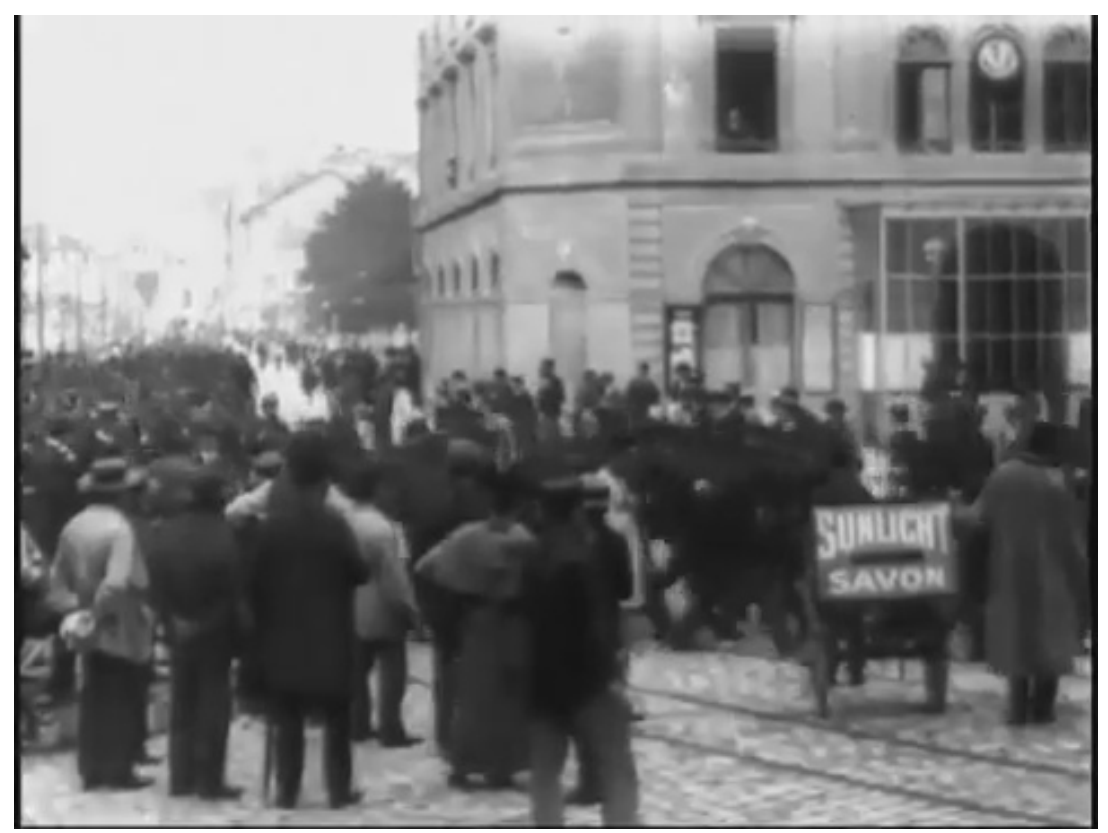

Fonte: Arquivo do autor

No campo da propaganda em videogames, um dos exemplos mais bem-sucedidos até hoje é a campanha presidencial norte-americana de 2008 do candidato Barak Obama, que envolveu o mercado jovem publicitando anúncios em jogos como o Burnout Paradise, do Xbox 360 (Imagem 2). A campanha apresentou anúncios em outdoors das pistas de corrida do jogo Burnout Paradise, que conseguindo engajar o público-alvo, através da adoção das mais recentes tecnologias e, posteriormente, marcando uma votação massiva de jovens nas eleições presidenciais (COCLES, 2009).

Figura 2 - Tela do videogame Burnout Paradise de 2008

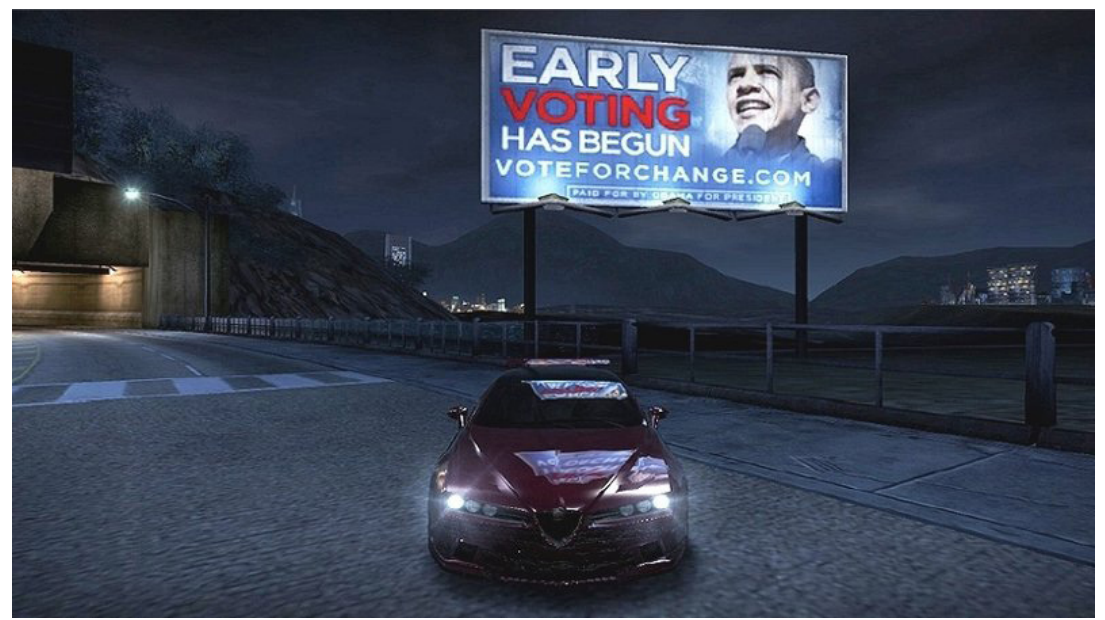

Fonte: Arquivo do autor 
Na nova mídia, o posicionamento do produto se infiltrou no Youtube, no Twitter e nos blogs. Celebridades foram contratadas para linkar sua persona às produtos no Twitter (GOULD; DELGADO, 2011). O entretenimento de marca é abundante no Youtube, por isso, as postagens de blogs são patrocinadas dentro da blogosfera.

\section{Definições de product placement}

Apresentamos uma visão geral das principais definições de product placement dos últimos 20 anos (Quadro Geral). Estas definições analisadas foram classificadas de acordo com o ano de publicação dos artigos, bem como o tipo de mídia usado na análise do artigo. O ano de publicação nos auxilia a situar a evolução das definições do product placement. A apresentação de tipos de mídia permitiu que essas definições fossem colocadas em um contexto de domínio. Como mostrado no Quadro Geral, a maioria das pesquisas sobre product placement tem sido centrada em filmes, televisão e videogames. Isso é revelado pelo estudo de palavras recorrentes e dos descritores de mídia usados. No entanto, esse conjunto de conhecimentos evoluiu nos últimos anos à medida que novas tecnologias e tipos de mídia foram sendo introduzidos no cotidiano.

O que é perceptível, ao revisar as definições, é o uso recorrente dos termos "inclusão", "incorporação", "inserção" ou similar. As noções de comercialização expressas nas frases de "pago", "em troca de dinheiro/taxas/pagamento em dinheiro" ou similares também eram comuns a muitas definições. O tipo de mídia é outro elemento evidente em quase todas as definições do Quadro Geral.

Mais recentemente, termos como "programação de mídia de massa" e "mídia/ambiente de entretenimento" foram introduzidos na linguagem do marketing, presumivelmente para não restringir a definição do termo product placement e sua aplicação com base em tipos de mídia, já que, anunciantes e profissionais de marketing, começaram a usar o termo placement em contextos das mídias mais atuais (KARRH, 1998; WINKLER; BUCKNER, 2006; LEHU; BRESSOUD, 2008).

O procedimento C-OAR-SE criado por Rossiter (2002), para o desenvolvimento de escalas é considerado uma estrutura mais apropriada para a elaboração de definições, especificamente o composto OAR para a montagem da definição, onde o objeto $(\mathrm{O})$, o atributo (A) e a entidade avaliadora (R) são identificados e especificados conforme as definições compiladas no Quadro Geral. A parte objeto da definição é classificada como objeto singular concreto, onde há uma visão praticamente unânime do que o objeto é na perspectiva dos avaliadores. 
Conforme o autor, o product placement/brand é o objeto constituído por um conjunto de objetos homogêneos, como pacote de produtos, sinalização, mercadoria de marca comercial e mensagem de produto ou serviço. Apesar de não ser um único objeto, os objetos que compõem o product placement/brand são consistentes nas características singulares concretas.

A parte do atributo da definição é classificada como um atributo concreto. Isso ocorre quando os avaliadores entendem que há apenas uma característica que está sendo referida quando o termo product placement é utilizado (ROSSITER, 2002). Aqui, o atributo é "comercialização". Conforme evidenciado no Quadro Geral, a inclusão de product placement/brand é paga, seja monetariamente ou por outros meios promocionais, e para fins comerciais.

Por fim, a entidade avaliadora é classificada como avaliadores de grupo e é identificada como a amostra de consumidores dos diferentes tipos de mídia, tradicionais e não tradicionais. É a perspectiva deles do constructo que está sendo representado quando se olha para o product placement (ROSSITER, 2002). É importante notar que essa amostra de consumidores está posicionada em um contexto não comercial, ou seja, não é o consumidor de uma mensagem publicitária ou de marketing direto. O procedimento C-OAR-SE é fundamentado no racionalismo e baseia-se em argumentos lógicos, portanto, a validade do conteúdo é essencial depois que o construto é definido de forma abrangente, de modo a permitir um desenvolvimento preciso da escala.

Notadamente, Karrh (1998) consolidou e comparou as definições apresentadas por Balasubramanian (1994), Steortz (1987) e Baker e Crawford (1995), ele observa que o termo Brand placement é mais apropriado do que o termo mais comumente usado product placement, pois geralmente é a marca que está sendo destacada, em vez do produto (KARRH, 1998, p. 32). Esta é uma distinção importante, mas a maioria dos teóricos tipicamente vê ambos os termos sendo usados de forma intercambiável. A definição de Steortz (1987) era notada na medida em que excluía a natureza paga das colocações e só considerava os estímulos visuais dentro de sua esfera. Essa definição não reconheceu que as veiculações também poderiam ser incluídas no diálogo ou no áudio de fundo de qualquer produção, em que uma pergunta como-Você quer uma Coca-Cola?, na forma de uma proposta de um personagem para o outro. 
Quadro Geral das definições de Product Placement

\begin{tabular}{|c|c|c|}
\hline Autor(s) & Definição - ênfase adicionada & $\overline{\text { Mídia }}$ \\
\hline Steortz, 1987 (p.22) & $\begin{array}{l}\text { A inclusão de uma marca, produto, símbolos ou outra } \\
\text { ação de uma marca comercial em um filme, programa } \\
\text { de TV ou videoclipe. }\end{array}$ & Cinema e TV \\
\hline $\begin{array}{l}\text { Friedman, } 1991 \text { (p.83) in } \\
\text { Olsen \& Lanseng, } 2012\end{array}$ & $\begin{array}{c}\text { A colocação de mensagens comerciais em contextos } \\
\text { não promocionais, como filmes, televisão, teatro e } \\
\text { romances. }\end{array}$ & $\begin{array}{c}\text { Cinema, TV, Teatro } \\
\text { e Literatura }\end{array}$ \\
\hline $\begin{array}{c}\text { Nebenzhal \& Secunda, } \\
1993 \text { (p.2) }\end{array}$ & $\begin{array}{l}\text { O Product Placement (PPL) é definido como a inclusão } \\
\text { de produtos de consumo ou serviços em filmes } \\
\text { distribuídos nos cinemas pelos principais estúdios de } \\
\text { Hollywood em troca de pagamentos em dinheiro ou } \\
\text { pela exposição promocional recíproca dos filmes em } \\
\text { programas publicitários de profissionais de marketing. }\end{array}$ & Cinema e Filmes \\
\hline $\begin{array}{l}\text { Balasubramanian, } \\
1994 \text { (p.29) In, Dardis, } \\
\text { Schmierbach, \& Limperos, } \\
2012\end{array}$ & $\begin{array}{l}\text { Uma mensagem de produto paga, destinada a } \\
\text { influenciar o público de cinema (ou televisão) através } \\
\text { da introdução planejada e discreta de um produto de } \\
\text { marca em um filme (ou programa de televisão). }\end{array}$ & Cinema e TV \\
\hline $\begin{array}{c}\text { Baker \& Crawford, } 1995 \\
\text { (p.2) }\end{array}$ & $\begin{array}{l}\text { A inclusão de produtos comerciais ou serviços em } \\
\text { qualquer forma, em produções de televisão ou filmes } \\
\text { em troca de algum tipo de pagamento do anunciante. }\end{array}$ & Cinema e TV \\
\hline $\begin{array}{l}\text { Gupta \& Gould, } 1997 \\
\text { (p.37) }\end{array}$ & $\begin{array}{c}\text { O Product Placement envolve a incorporação de } \\
\text { marcas em filmes em troca de dinheiro ou de alguma } \\
\text { ação promocional ou de outro tipo de compensação } \\
\text { e é atualmente um dos muitos tipos de inclusão de } \\
\text { produtos ou marcas que incluem TV, rádio, videoclipes, } \\
\text { videogames, romances, peças e músicas, bem como } \\
\text { filmes. }\end{array}$ & $\begin{array}{l}\text { Filmes, TV, } \\
\text { Videogames, } \\
\text { Literatura, } \\
\text { Teatro, Música e } \\
\text { Videoclipe }\end{array}$ \\
\hline $\begin{array}{l}\text { Karrh, } 1998 \text { (p.33) } \\
\text { In, Dardis et al., } 2012\end{array}$ & $\begin{array}{l}\text { A inclusão paga de produtos de marca ou marcas, } \\
\text { através de meios de áudio e/ou visuais, dentro da } \\
\text { programação de mídia de massa. }\end{array}$ & $\begin{array}{l}\text { Filmes, TV, música } \\
\text { e videoclipes }\end{array}$ \\
\hline $\begin{array}{l}\text { D’Astous \& Seguin, } 1999 \\
\text { (p. 897) } \\
\text { In Homer, 2009 } \\
\end{array}$ & $\begin{array}{c}\text { A colocação de uma marca ou empresa em um filme ou } \\
\text { em um programa de televisão por diferentes meios e } \\
\text { para fins promocionais. }\end{array}$ & Filmes e TV \\
\hline $\begin{array}{l}\text { Balasubramanian et al, } \\
2006 \text { (p. 115) } \\
\text { In, Homer, 2009 }\end{array}$ & $\begin{array}{l}\text { Apresentação de marcas que representam esforços } \\
\text { promocionais deliberados, reforçados por acordos } \\
\text { formais entre profissionais de marketing e criadores/ } \\
\text { gerentes de conteúdo editorial. }\end{array}$ & Filmes e TV \\
\hline $\begin{array}{l}\text { Winkler \& Buckner, } 2006 \\
\text { (p. 24) }\end{array}$ & $\begin{array}{l}\text { O termo Product Placement é usado para se referir ao } \\
\text { posicionamento de imagens de uma marca ou produto } \\
\text { em um meio de entretenimento, como um jogo on-line. }\end{array}$ & Videogame \\
\hline Glass, 2007 (p. 23) & $\begin{array}{l}\text { Como técnica publicitária, o Product Placement } \\
\text { envolve a inserção de uma marca ou produto em um } \\
\text { filme, programa de televisão, livro ou videogame. }\end{array}$ & $\begin{array}{l}\text { Filme, TV, } \\
\text { Literatura e } \\
\text { Videogame } \\
\end{array}$ \\
\hline $\begin{array}{c}\text { Lehu \& Bressoud, } 2008 \text { (p. } \\
1083-4)\end{array}$ & $\begin{array}{l}\text { O Product Placement é uma técnica de mestiçagem que } \\
\text { combina diferentes técnicas de comunicação, ocorrendo } \\
\text { em um ambiente cultural e/ou de entretenimento. }\end{array}$ & $\begin{array}{l}\text { Filmes, TV, Games, } \\
\text { Música, Literatura, } \\
\text { Teatro e Videoclipe }\end{array}$ \\
\hline
\end{tabular}




\begin{tabular}{|c|c|c|}
\hline $\begin{array}{c}\text { Ginosar \& Levi-Faur, 2010 } \\
\text { (p. 467) }\end{array}$ & $\begin{array}{c}\text { O Product Placement é a incorporação intencional de } \\
\text { conteúdo comercial em ambientes não comerciais, ou } \\
\text { seja, um plug de produto gerado por meio da fusão de } \\
\text { publicidade e entretenimento. }\end{array}$ & $\begin{array}{l}\text { Filmes, TV, Games, } \\
\text { Música, Literatura, } \\
\text { Teatro e Videoclipe }\end{array}$ \\
\hline Williams et al, 2011 (p. 2) & $\begin{array}{c}\text { Product placement - também conhecido por } \\
\text { Product Brand Placement - patrocínio de programas, } \\
\text { entretenimento de marcas, ou integração de produtos, } \\
\text { é uma prática de marketing na publicidade e na } \\
\text { promoção, em que uma marca, produto, pacote, } \\
\text { sinalização ou outra marca registrada e merchandising, } \\
\text { usada contextualmente em um filme, televisão ou outro } \\
\text { veículo de mídia para fins comerciais. }\end{array}$ & $\begin{array}{c}\text { Música, Teatro e } \\
\text { Videoclipe }\end{array}$ \\
\hline
\end{tabular}

Fonte: Elaborado pelo autor.

Como se vê no quadro apresentado, a definição de product placement não deve se limitar à sinalização, marca registrada e/ou ao próprio produto. Balasubramanian (1994) e Baker e Crawford (1995) reconheceram a natureza paga dos product placements, mas limitaram a mídia envolvida ao cinema e à televisão. Essa é, evidentemente, uma limitação inadequada para veiculações de produtos, pois sempre existiu e nos últimos anos se tornou cada vez mais popular entre os anunciantes o uso de outros veículos. Karrh (1998) observa as limitações dos tipos de mídia, explicando que outros tipos de mídia, como videogames, romances, músicas e teatro, não foram incluídos como parte das definições originais. Definições mais recentes incorporaram termos mais gerais, como "ambiente de entretenimento/mídia" e até "outro veículo de mídia", na tentativa de não excluir outros tipos de mídia (LEHU e BRESSOUD, 2008; WILLIAMS, PETROSKY, HERNANDEZ e PAGE, 2011; WINKLER e BUCKNER, 2006). Essa generalização do ambiente em que os product placements são colocados é considerada mais apropriada para a atual situação de publicidade contemporânea.

Karrh (1998) também aponta que o termo "não intrusivo", conforme expresso na definição de Balasubramanian (1994), pode se tornar irrelevante, uma vez que certas inserções de marcas são usadas para funções deliberadas ou abertas. Por exemplo, marcas específicas podem ser usadas para acentuar a personalidade do personagem, definir elementos de uma cena ou período de tempo ou para funções promocionais (KARRH, 1998). Karrh ainda diferencia uma marca "colocada" e uma marca que é "incluída" em um programa. Aqui, o autor refere-se à descrição de Friedman (1991) do brand placement como “publicidade de palavra de autor", onde nomes de marcas são usados dentro dos textos de mídia (p. 83). Para diferenciar se as colocações são "comercialmente inspiradas" ou não, Friedman usa o termo "publicidade de palavra de autor patrocinada" e "publicidade de 
palavra de autor não patrocinada" (p. 83). Essa distinção se baseia na intenção do criador do programa e muitas vezes é invisível para o público-alvo.

Apesar dessas valiosas distinções, é importante destacar que as definições analisadas por Karrh (1998) estão ultrapassadas. O foco dele estava no trabalho de pesquisa antes da era da internet, onde a mídia de massa era a principal arena para o product placement. Evidentemente, as definições propostas nos últimos anos levaram em conta um cenário de mídia em constante mudança e consideram o product placement como um híbrido de publicidade, entretenimento e relações públicas. Novos tipos de mídia, como mundos virtuais on-line, blogs, etc., precisam ser levados em consideração.

Uma contribuição valiosa foi feita por D’Astous e Seguin (1999) quando propuseram que, no patrocínio da televisão, o product placement pode ser classificado em três tipos principais: implícito, explícito integrado e não integrado explícito. O posicionamento implícito do produto desempenha um papel passivo e contextual no qual o produto/ marca não é formalmente expresso ao público. O posicionamento explícito integrado, no entanto, é formalmente expresso e, portanto, desempenha um papel ativo, onde os benefícios e atributos do produto são claramente demonstrados para o público. Por outro lado, a colocação explícita e não integrada de produtos é formalmente expressa, mas não incluída no conteúdo do programa. Por exemplo, programas de televisão são iniciados com um anúncio "Este programa é trazido a você por marca X" ou Apoio cultural de XX. Observa-se que essa classificação não se limita ao product placement na televisão. Posicionamentos explícitos, implícitos e integrados são os principais tipos vistos em filmes em que o produto, serviço ou marca podem ser estímulos auditivos ou visuais e apenas mencionados, exibidos ou interagidos no contexto dos filmes. No entanto, todos os três tipos de veiculações de produtos podem ser inferidos em jogos, vídeos do YouTube, postagens de blogs patrocinados e até plugues do Twitter.

No caso apresentado do outdoor no videogame da campanha de Obama é um product placement implícito, exibido como parte do ambiente do jogo, enquanto posts patrocinados demonstram veiculações explícitas integradas, já que o produto, serviço ou marca geralmente são formalmente expressos, juntamente com seus benefícios e atributos. Por fim, canais explícitos não integrados, são praticados em jogos e vídeos do YouTube da mesma forma que para programas de televisão. Portanto, isso levanta a questão se existe uma distinção entre estratégias de product placement na programação da mídia de massa e das atuais estratégias dinâmicas de comunicação de marketing. 
Devido a mudanças tecnológicas ocorridas nos últimos 20 anos, a forma como o consumidor recebe e se envolve com a publicidade e com as marcas se tornou cada vez mais complexa e parece estar mudando constantemente em um ritmo radical. Este cenário midiático em mutação alterou os objetivos de comunicação das marcas. Hoje elas se esforçam para ser mais transparentes e estão mais avessas ao risco, adotando novos formatos de publicidade, como campanhas de internet viral e propaganda de guerrilha. Assim, é importante pensar essas mudanças em relação à finalidade e a função do product placement, investigando a coerência entre o seu uso com as estratégias de comunicação contemporâneas.

Com base na revisão de literatura, no Quadro Geral de definições e na implementação da estrutura OAR para a montagem da definição (de acordo com procedimento C-OAR-SE), chegamos a alguns pontos conclusivos:

1. A classificação das estratégias de product placement para a mídia tradicional transcende o tipo de mídia e pode ser aplicada tanto à mídia tradicional quanto às mais novas. A principal premissa do product placement é retratar a realidade, portanto, sua função-chave é integrar-se à narrativa da forma mais perfeita possível.

2. As definições de product placement de anos anteriores incluíram tipos limitados de mídia, no entanto, as definições mais recentes tentaram incluir os tipos de mídia mais contemporâneos e em constante evolução por serem menos específicos e mais gerais.

3. Por fim, usando o framework OAR, um objeto singular concreto, um atributo concreto e um avaliador de grupo foram identificados, permitindo uma definição mais abrangente do termo product placement.

Decorrente da revisão de definições anteriores para product placement, podemos defender uma nova proposta para defini-lo apresentada como sendo a incorporação de produtos ou marcas em contextos não comerciais em uma abordagem planejada e não intrusiva para fins comerciais. Essa definição alterada inclui o objeto concreto (product placement), o atributo concreto (comercialização), a função-chave do product placement/brand (abordagem planejada e não intrusiva), bem como um termo não limitativo para tipos de mídia (contextos não comerciais), que também é usado para formar a entidade avaliadora.

Com essa definição refinada, o termo product placement pode ser usado para representar o objeto concreto, que é composto por um conjunto de produtos homogêneos, sinalização, marca comercial ou qualquer outra mensagem relacionada ao produto/marca, 
tanto visual quanto auditivo ou mesmo relaciona-lo a outros sentidos como o olfato o tato ou o paladar. Isso é uma melhoria das definições existentes, pois não se limita a menções específicas de tipos de veiculação de produtos. O atributo concreto do product placement é a comercialização, declarada na maioria das definições do Quadro Geral. No entanto, o termo "fins comerciais" foi escolhido de forma a representar a natureza paga, seja em troca de dinheiro ou outro ganho promocional, do product placement de uma forma mais concisa. Depois de detectados, os consumidores mais experientes de hoje geralmente entendem e aceitam veiculações de produtos como publicidade ou mensagem de marca por meio do conteúdo da mídia. Assim, neste caso, as definições que especificam a natureza comercial da colocação de produtos, tais como Friedman (1991), Ginosar e Levi-Faur (2010) e Williams et al (2011) são favorecidas. Esse termo conciso também ajudará a contrastar com o contexto não publicitário de onde os canais de produtos são colocados. Os diferentes tipos de mídia em que os canais de produtos aparecem como filmes, televisão, jogos, Twitter e outros veículos de mídia, foram resumidos em um termo mais simples "contextos não comerciais". Aqui, o uso dos termos "contextos não promocionais" e "ambientes não comerciais" são preferidos, pois elimina a possibilidade de excluir veículos de novas mídias neste cenário em que as mídia estão em constante mudança.

A definição proposta incorpora desenvolvimentos de colocações de produtos no novo reino da mídia. Mudanças no cenário da mídia fizeram com que a classificação dos tipos de mídia acima da linha e abaixo da linha ficasse redundante. Uma nova maneira de segmentar a mídia, como o arcabouço pago, próprio, ganhado, promovido e compartilhado, surgiu (SOLIS, 2011). O autor ainda diz que à medida que as marcas se tornam histórias, os consumidores se tornam contadores de histórias, e esses meios são onde essas histórias são compartilhadas, conectadas e integradas à narrativa. Toda a mídia é diferente e a maneira como os consumidores usam a mídia está sempre evoluindo. Após mudanças no comportamento do consumidor está a mudança na forma como as marcas se envolvem com os consumidores, mudando assim os objetivos e estratégias de comunicação de marketing (WEINBERG; PEHLIVAN, 2011).

Assim que o tipo de posicionamento do produto for identificado, o "como" e "por que" destes posicionamentos utilizados podem ser avaliados com maior precisão. A compreensão do que é a colocação de produto e o exame abrangente do construto é de vital importância para a investigação da colocação de produtos na nova esfera de mídia digital, que ainda é uma área consideravelmente emergente para os pesquisadores. 


\section{Considerações finais}

As principais contribuições do documento foram delineadas especialmente na conciliação das literaturas limitadas sobre colocações de produtos, particularmente na área de novas mídias. Ao investigar o domínio sistematicamente, uma nova definição de colocação de produtos é proposta. Assim, uma coerência entre a colocação de produtos e o mundo da publicidade contemporânea é estabelecida. No entanto, os novos tipos de mídia aumentaram o poder dos consumidores como produtores de conteúdo, em vez de meros consumidores passivos de publicidade. Um tema valioso para pesquisas futuras implica investigar o papel das colocações de produtos / marcas como conteúdo, particularmente nas áreas de novos tipos de mídia, como blogs, mídias sociais e jogos interativos (OLSEN; LANSENG, 2012). De interesse são características e como os consumidores utilizam vários tipos de mídia. Isso permitirá um melhor entendimento de como a colocação de produtos funcionará com mais eficiência. $\mathrm{O}$ objetivo final desses estudos será esclarecer as implicações gerenciais e práticas para anunciantes e marcas para o uso efetivo da colocação de produtos.

\section{Referências}

AMERICAN MARKETING ASSOCIATION (AMA). Dictionary of Marketing Terms. Disponível em: https://www.ama.org/resources/Pages/Dictionary.aspx. Acesso em: 25.set.2017.

BAKER, M. J.; CRAWFORD, H. A. Product Placement. Department of Marketing, University of Strathclyde, Glasgow, Scotland. 1995. Disponível em: http://hdl.handle.net/10068/442050. Acesso em 21.mar.2018.

BALASUBRAMANIAN, S. K. Beyond Advertising and Publicity: Hybrid Messages and Public Policy Issues. Journal of Advertising, 23. Dez. 1994, p. 29-46.

COCLES. Viral Video Game Advertising. Viral Conversations: Get People Talking About Your Products. 2009. Disponível em: http://www.viralconversations.com/articles/viral-game-advertising-00726. Acesso em: 15. mar. 2018.

D'ASTOUS, A.; SEGUIN, N. Consumer reactions to product placement strategies in television sponsorship. European Journal of Marketing, v. 33, n. 9/10, 1999, p. 896-910. 
DARDIS, F. E.; SCHMIERBACH, M., e LIMPEROS, A. M. The Impact of Game Customization and Control Mechanisms on Recall of Integral and Peripheral Brand Placements in Video Games. Journal of Interactive Advertising, v. 12, n. 2, 2012, p. 1-12.

FRIEDMAN, M. A “Brand” New Language. New York: Greenwood Press. 2012.

GINOSAR, A.; LEVI-FAUR, D. Regulating Product Placement in the European Union and Canada: Explaining Regime Change and Diversity. Journal of Comparative Policy Analysis, 12(5). 2010, p. 467-490.

GOUlD, L.; DELGADO, M. Stop Tweeting - Or We Will Take You To Court! Watchdog's Crackdown on Celebrities Who Plug Products on Twitter. 2011, January 9 Daily Mail Online. Disponível em: http://www.dailymail.co.uk/news/article-1345382/Twitter-Liz-Lurley- LilyAl-len-face-possible-court-action-endorsing-luxury-items.html. Acesso em: 15. 03. 2018.

GUPTA, P. B.; GOULD, S. J. Consumers' Perceptions of the Ethics and Acceptability of Product Placements in Movies: Product Category and Individual Differences. Journal of Current Issues and Research in Advertising, v. 19, n. 1, 1997, p. 37-50.

HOMER, P. M. Product Placements: The Impact of Placement Type and Repetition on Attitude. Journal of Advertising, v. 38, n. 3, 2009, p. 21-31.

KARRH, J. A. Brand Placement: A Review. Journals of Current Issues and Research in Advertising, 20(2), 1998, p. 31-49.

KERN, A. L. Blowing smoke: Tobacco pouches, literary squibs, and authorial puffery in the pic-torial comic fiction (Kibyoshi) of Santo Kyoden (1761-1816). Harvard University, Cambridge, MA.1997.

LEHU, J.-M. e BRESSOUD, E. Effectiveness of Brand Placement: New Insights About Viewers. Journal of Business Research, v. 61, n. 10, 2008, p. 1083-1090.

LEHU, Jean-Marc. Branded Entertainment: Product Placement \& Brand Strategy in the Enter-tainment Business. London: Kogan Page. 2007

LIEBENSON, D. Look Familiar? Brand Names Stake A Claim in Film. The Chicago Tri-bune. 06. dez. 1990. Disponível em: http://articles.chicagotribune.com/1990-12-06/ featu-res/9004100939_1_product-placement-risky-business-coke. Acesso em: 15 mar. 2018. 
NEBENZHAL, I. D.; SECUNDA, E. Consumers' Attitudes Toward Product Placement in Movies. International Journal of Advertising, v. 12, n. 1, 1993, p. 1-11.

NEWELL, Jay; Charles T. SALMON e Susan CHANG. The Hidden History of Product Place-ment. Journal of Broadcasting \& Electronic Media 50, n. 4, 2006, p. 575-594.

OLSEN, L. E.; LANSENG, E. J. Brands In Texts: Attitudinal Effects of Brand Placements In Narrative Fiction. Journal of Brand Management, v. 19, n. 8, 2012, p. 702-711.

REED, J. D. Plugging Away in Hollywood. Time, 103. 02, January. 1989.

ROSSITER, J. R. The C-OAR-SE Procedure For Scale Development In Marketing. International Journal of Research in Marketing, v. 19, n. 4, 2002, p. 305-335.

SOLIS, B. Brian Solis. Looking Beyond Paid, Earned, Owned Media: The Brandsphere Infographic. 2011. Disponível em: inforgraphic-the-brandsphere-by-brian-solis-and-jess3/. Acesso em: 15 mar. 2018.

STEORTZ, E. M. The Cost Efficiency and Communication Effects Associated with Brand Name Exposure Within Motion Pictures. Dissertação de mestrado. West Virginia University. 1987.

WEINBERG, B. D.; PEHLIVAN, E. Social Spending: Managing the Social Media Mix. Business Horizons, v. 54, n. 3, 2011, p. 275-282.

WILLIAMS, K. et al. Product Placement Effectiveness: R evisited a nd R enewed. J ournal of Management and Marketing Research, 7(Abril), 2011, pp.1-24.

WINKLER, T.; BUCKNER, K. Receptiveness of Gamers to Embedded Brand Messages In: Advergames: Attitudes Towards Product Placement. Journal of Interactive Advertising, v. 7. 2006, p. 24-32. Disponível em: http://www.jiad.org/vol7/ no1/winkler/index.htm. Acesso em: 15 mar. 2018. 